\title{
Efficacy and safety of erenumab in women with a history of menstrual migraine
}

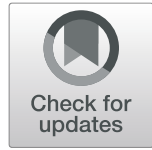

Jelena M. Pavlovic ${ }^{1,2^{*}}$, Koen Paemeleire ${ }^{3}$, Hartmut Göbel ${ }^{4}$, Jo Bonner ${ }^{5}$, Alan Rapoport ${ }^{6}$, Risa Kagan ${ }^{7,8}$, Feng Zhang ${ }^{9}$, Hernan Picard ${ }^{9}$ and Daniel D. Mikol ${ }^{9}$

\begin{abstract}
Background: We performed a post hoc, subgroup analysis of a phase 3, randomized, double-blind, placebocontrolled study of erenumab for prevention of episodic migraine (STRIVE) to determine the efficacy and safety of erenumab in women with self-reported menstrual migraine.
\end{abstract}

Methods: Patients received placebo, erenumab $70 \mathrm{mg}$, or erenumab $140 \mathrm{mg}$ subcutaneously once monthly during the 6-month double-blind treatment phase of STRIVE. Women who reported history of menstrual migraine and who were $\leq 50$ years old were included in the analysis. Endpoints were change from baseline in monthly migraine days (MMD) and monthly acute migraine-specific medication days (MSMD; among patients who took acute migraine-specific medications at baseline), proportion of patients achieving $\geq 50 \%$ reduction from baseline in MMD, and incidence of adverse events.

Results: Among 814 women enrolled in STRIVE, 232 (28.5\%) reported a history of menstrual migraine and were $\leq 50$ years old. Of the 232 patients, 214 (92\%) had a baseline MMD > 5, suggesting a high proportion of women with attacks outside of the 5-day perimenstrual window ( 2 days before and 3 days after the start of menstruation). Information on "migraine days" includes (and does not discriminate between) perimenstrual and intermenstrual migraine attacks. Between-group differences from placebo over months 4-6 for erenumab $70 \mathrm{mg}$ and $140 \mathrm{mg}$ were $-1.8(P=0.001)$ and $-2.1(P<0.001)$ days for MMD and - $1.6(P=0.002)$ and $-2.4(P<0.001)$ days for acute $M S M D$, respectively. The odds of having a $\geq 50 \%$ reduction from baseline in MMD over months 4-6 were 2.2 $(P=0.024)$ and $2.8(P=0.002)$ times greater for erenumab $70 \mathrm{mg}$ and $140 \mathrm{mg}$, respectively, than for placebo. Erenumab had an overall safety profile comparable to placebo.

Conclusion: Data from this subgroup analysis of women with menstrual migraine are consistent with data from the overall STRIVE episodic migraine population, supporting the efficacy and safety of erenumab in women who experience menstrual migraine.

Trial registration: ClinicalTrials.gov, NCT02456740. Registered 28 May 2015.

Keywords: Erenumab, Headache, Episodic migraine, Migraine prevention, Pure menstrual migraine, Menstrually related migraine, Perimenstrual attacks

\footnotetext{
* Correspondence: jpavlovi@montefiore.org

'Department of Neurology, Montefiore Headache Center, 1300 Morris Park

Avenue, Van Etten 3C9, Bronx, NY 10461, USA

${ }^{2}$ Albert Einstein College of Medicine, Bronx, NY, USA

Full list of author information is available at the end of the article
}

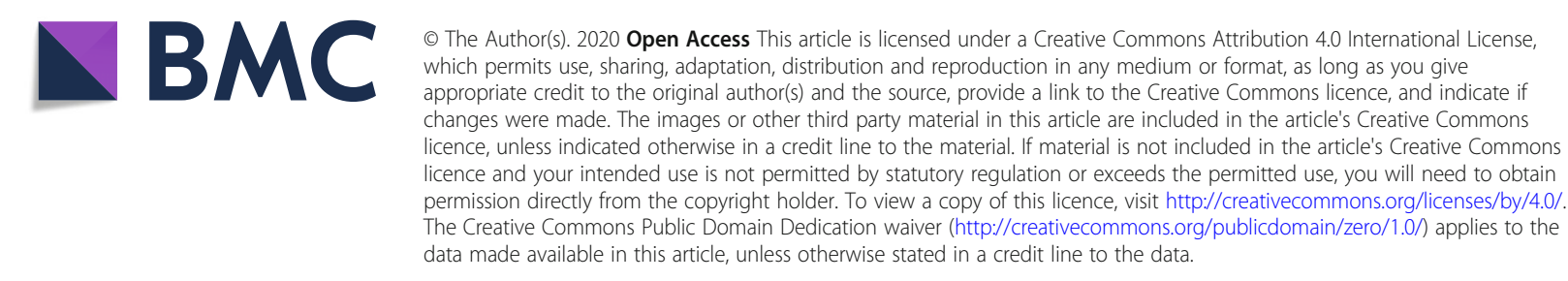




\section{Background}

More than $50 \%$ of women self-report an association between migraine and menses [1]. These perimenstrual attacks are commonly referred to as menstrual migraine if they occur within a 5-day window (2 days prior to menstruation and the first 3 days of menstruation). Menstrual migraine attacks are particularly burdensome, as they tend to be of longer duration [2-7] and are more severe and disabling [2, 3, 5, 7-9] than non-perimenstrual attacks. Furthermore, perimenstrual attacks are less responsive to acute therapy, making them difficult to treat $[2,4,5]$.

Women who experience migraine attacks with the majority of their menstrual periods (defined by The International Classification of Headache Disorders [ICHD] 3 beta [10] as at least two of three periods) are classified into either pure menstrual migraine (PMM; attacks that occur only during the 5-day perimenstrual window) or menstrually related migraine (MRM; attacks that occur during the 5-day perimenstrual window and at other times of the cycle). PMM is a rare condition that affects approximately $5 \%-8 \%$ of women with migraine $[9,11,12]$, with most women self-reporting MRM [4]; however, the percentage varies widely depending on the study populations and diagnostic criteria used $[2,4,11,13]$.

There are no approved, specific preventive treatments for menstrual migraine. It has been proposed that women who do not respond to acute treatment options may be eligible to receive either short-term or long-term preventive treatments [14]. Several medications, including triptans, nonsteroidal anti-inflammatory drugs, cyclooxygenase-2 inhibitors, and estrogen supplementation, have been investigated for shortterm prevention of menstrual migraine; however, these agents may delay rather than prevent attacks [14]. Longterm preventive treatment for menstrual migraine has been investigated with topiramate, which reduced the frequency but not the severity or duration of perimenstrual attacks [15]. Continuous use of hormonal contraceptives can reduce the severity and duration of migraine attacks [14, 16-18]. Although hormonal contraceptives containing estrogens are considered a viable treatment option for women with menstrual migraine [19], evidence of their effectiveness is limited [20], and they may be contraindicated because of their association with increased risk of stroke [21-24]. According to the current guidelines, exogenous estrogens are contraindicated in all women with migraine with aura and in women with migraine without aura who are smokers and/or older than 35 years of age [25-27]; estrogen-containing options are therefore often not available to most women with migraine aged 35 or older $[25,26]$.

The challenges associated with the treatment of menstrual migraine emphasize the need for novel, nonhormonal, long-term preventive treatments. Erenumab is a fully human monoclonal antibody that selectively targets and blocks the canonical calcitonin gene-related peptide
(CGRP) receptor [28]. In the 6-month double-blind treatment phase of the STRIVE trial of patients with episodic migraine, erenumab at $70 \mathrm{mg}$ or $140 \mathrm{mg}$ once monthly significantly reduced the number of monthly migraine days (MMD) and monthly acute migraine-specific medication days (MSMD) and increased the odds of achieving $\geq 50 \%$ reduction from baseline in MMD [29]. Given the burden and challenges in the treatment of menstrual migraine, we performed a post hoc subgroup analysis of STRIVE to determine the efficacy and safety of erenumab in women with self-reported menstrual migraine.

\section{Methods}

\section{Study design and patients}

STRIVE (ClinicalTrials.gov, NCT02456740) was a phase 3 , randomized, double-blind, placebo-controlled study of erenumab in patients with episodic migraine [29]. In brief, the study consisted of a 7-week screening phase (including 4 weeks of baseline), a 6-month double-blind treatment phase, a 7-month dose-blinded active treatment phase, and a 3-month safety follow-up phase. Randomization was stratified by region (North America vs other) and prior preventive medication status (naïve vs prior use vs concomitant use). Placebo and erenumab $70 \mathrm{mg}$ and $140 \mathrm{mg}$ were administered subcutaneously once every month during the double-blind treatment phase; erenumab $70 \mathrm{mg}$ or $140 \mathrm{mg}$ were administered during the 28-week active treatment phase.

Eligible patients were 18-65 years old with a history of migraine with or without aura (based on medical records and/or self-reported) for at least 12 months before screening. Episodic migraine was defined as an average of 4-14 migraine days per month with fewer than 15 headache days per month (in accordance with ICHD3 ) during the 3 months before screening and during the 4-week baseline phase of the study. One concomitant migraine-preventive medication was allowed following a protocol amendment that was introduced late during the enrollment period. Patients were excluded if they had no therapeutic response to $>2$ migrainepreventive treatment categories, defined as no reduction in headache frequency, duration, or severity after administration of the medication for at least 6 weeks at the generally accepted therapeutic dose(s) based on the investigator's assessment.

The study protocol was approved by the ethics committee or institutional review board at each clinical site, and all patients provided signed informed consent before the start of any study-related procedures. The study was conducted in accordance with the International Council for Harmonisation Good Clinical Practice Guidelines and conforms to the provisions of the Declaration of Helsinki. 


\section{Menstrual migraine subgroups}

Women were asked if they had migraine attacks that occurred within a 5-day window (2 days prior to menstruation and the first 3 days of menstruation) in at least 2 out of the last 3 menstrual cycles prior to screening in accordance with the criteria for menstrual migraine diagnosis [10]. In industrialized countries, the average age for onset of perimenopause is 47.5 years and is influenced by several demographic, lifestyle, and biologic factors [30]. Based on this, for the current subgroup analysis, we included menstruating women aged $\leq 50$ years with a self-reported history of menstrual migraine attacks. Since the data collected did not allow us to distinguish between women who had only menstrual attacks (PMM) and those who had both menstrual and non-menstrual attacks (MRM), both categories are included under the label "menstrual migraine" in our analyses.

\section{Endpoints}

Efficacy endpoints were change from baseline in mean MMD, change from baseline in mean monthly acute MSMD among patients who took acute migraine-specific medications at baseline, and the proportion of patients achieving $\mathrm{a} \geq 50 \%$ reduction from baseline in MMD (proportion of responders). Efficacy was assessed for each monthly interval from data collected daily using the patients' electronic diaries; the primary time point of assessment in the study was the average monthly effect over months 4-6. Analysis of migraine frequency-related endpoints includes all (both perimenstrual and intermenstrual) migraine days.
Safety was monitored throughout the study, and adverse events were coded according to the Medical Dictionary for Regulatory Activities version 19.0.

\section{Statistical analysis}

Change from baseline in MMD and monthly acute MSMD was analyzed using a generalized linear mixed effects model, which included treatment, visit, treatment by visit interaction, stratification factors (North America/other and naïve/prior use/concomitant use), and baseline value as covariates and assumed a first-order autoregressive covariance structure; missing data were not imputed. The proportion of responders was analyzed using a stratified Cochran-Mantel-Haenszel test after imputation of missing data as nonresponse. $P$ values for the between-group differences (erenumab $70 \mathrm{mg}$ and $140 \mathrm{mg}$ vs placebo) are nominal $P$ values without multiplicity adjustment. Statistical significance was determined based on the comparison of the nominal $P$ values with a significance level of 0.05 .

\section{Results}

Patient characteristics

Among 814 women enrolled in STRIVE, 232 (28.5\%) self-reported a history of menstrual migraine and were $\leq 50$ years old. Baseline characteristics were fairly balanced among the treatment groups (Table 1).

Of the 232 women with menstrual migraine, 65 (28\%) were taking oral contraceptives/hormone therapy during

Table 1 Baseline characteristics

\begin{tabular}{|c|c|c|c|c|}
\hline & \multicolumn{4}{|c|}{ History of Menstrual Migraine } \\
\hline & $\begin{array}{l}\text { Placebo } \\
\boldsymbol{N}=83\end{array}$ & $\begin{array}{l}\text { Erenumab } 70 \mathrm{mg} \\
\mathbf{N}=68\end{array}$ & $\begin{array}{l}\text { Erenumab } 140 \mathrm{mg} \\
\boldsymbol{N}=81\end{array}$ & $\begin{array}{l}\text { All Patients } \\
\boldsymbol{N}=232\end{array}$ \\
\hline Age, years, median (range) & $37(20-49)$ & $38(21-50)$ & $37(19-50)$ & $37(19-50)$ \\
\hline \multicolumn{5}{|l|}{ Race, n (\%) } \\
\hline White & $71(86)$ & $61(90)$ & $77(95)$ & $209(90)$ \\
\hline Black or African American & $3(4)$ & $5(7)$ & $2(3)$ & $10(4)$ \\
\hline Asian & $4(5)$ & $0(0)$ & $2(3)$ & $6(3)$ \\
\hline Other & $5(6)$ & $2(3)$ & $0(0)$ & $7(3)$ \\
\hline Migraine with aura, ${ }^{a} \mathrm{n}(\%)$ & $48(58)$ & $35(52)$ & $38(47)$ & $121(52)$ \\
\hline Migraine without aura, ${ }^{a} \mathrm{n}(\%)$ & $71(86)$ & $61(90)$ & $72(89)$ & $204(88)$ \\
\hline Received hormonal contraception, n (\%) & $20(24)$ & $18(26)$ & $27(33)$ & $65(28)$ \\
\hline \multicolumn{5}{|l|}{ Treatment with migraine-preventive medication, $\mathrm{n}(\%)$} \\
\hline Naïve & $50(60)$ & $37(54)$ & $48(59)$ & $135(58)$ \\
\hline Prior and/or concomitant use & $33(40)$ & $31(46)$ & $33(41)$ & $97(42)$ \\
\hline \multicolumn{5}{|l|}{ Baseline phase (4 weeks) } \\
\hline Monthly migraine days, mean (SD) & $8.6(2.8)$ & $8.3(2.4)$ & $8.4(2.4)$ & $8.4(2.5)$ \\
\hline Monthly acute migraine-specific medication days, mean (SD) & $3.2(3.5)$ & $3.1(3.1)$ & $3.7(3.6)$ & $3.3(3.4)$ \\
\hline Acute migraine-specific medication use, $\mathrm{n}(\%)$ & $48(58)$ & $38(56)$ & $51(63)$ & $137(59)$ \\
\hline
\end{tabular}

aased on self-report; categories are not mutually exclusive Abbreviations: SD standard deviation 
the study: 18 (26\%) in the erenumab $70 \mathrm{mg}$ group, 27 (33\%) in the erenumab $140 \mathrm{mg}$ group, and 20 (24\%) in the placebo group.

\section{Efficacy}

\section{Change from baseline in mean monthly migraine days}

During the study, both doses of erenumab resulted in statistically significantly greater reductions vs placebo in MMD as early as month 1 (Fig. 1). The mean MMD reduction over months $4-6$ was $-1.4,-3.2$, and -3.5 days in the placebo, erenumab $70 \mathrm{mg}$, and erenumab $140 \mathrm{mg}$ groups, respectively (Table 2). Differences from placebo were statistically significant: $-1.8 \quad(P=0.001)$ and -2.1 $(P<0.001)$ days for the erenumab $70 \mathrm{mg}$ and $140 \mathrm{mg}$ groups, respectively (Table 2 ).

An analysis of MMD was performed for patients who were receiving exogenous hormones for contraception versus those who were not receiving exogeneous hormones (Table 3). Overall, the subgroup of patients receiving exogenous hormones had similar efficacy results compared to the total population with a history of menstrual migraine.

\section{Change from baseline in monthly acute migraine-specific medication days}

In the subgroup of patients who were taking acute migraine-specific medications at baseline, erenumab $70 \mathrm{mg}$ and $140 \mathrm{mg}$ vs placebo resulted in greater reductions in monthly acute MSMD starting at month 1 ; reductions were statistically significant at every month for the $140-\mathrm{mg}$ dose group (Fig. 2). The mean reduction in monthly acute MSMD over months 4-6 was 0.4, 2.0, and 2.8 days in the placebo, erenumab $70 \mathrm{mg}$, and erenumab $140 \mathrm{mg}$ groups, respectively (Table 2). Differences from placebo were statistically significant: $-1.6(P=0.002)$ and $-2.4(P<0.001)$ days for the erenumab $70 \mathrm{mg}$ and $140 \mathrm{mg}$ groups, respectively (Table 2).

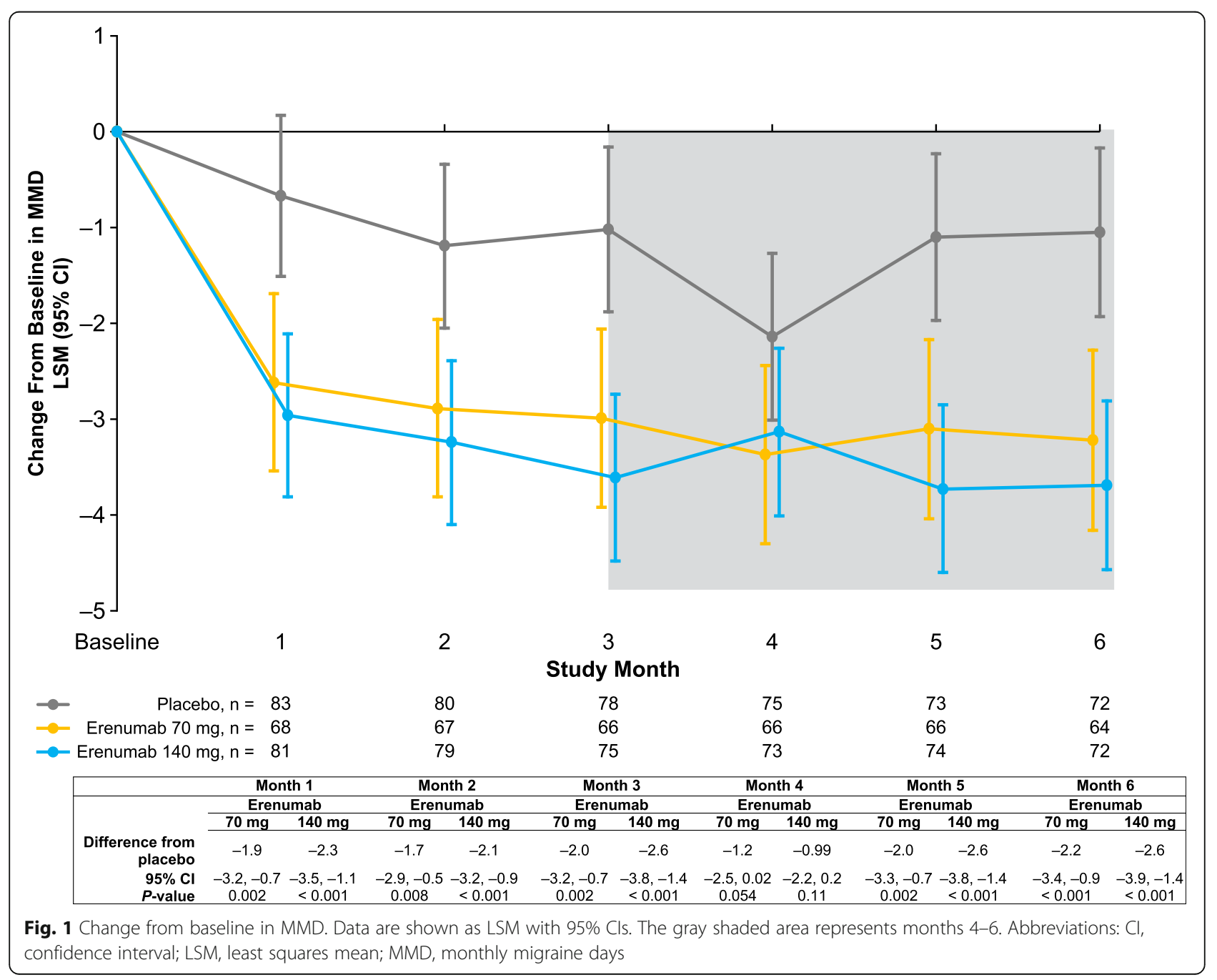


Table 2 Efficacy over months 4-6 of the double-blind treatment phase

\begin{tabular}{llll}
\hline & $\begin{array}{l}\text { Placebo } \\
\mathbf{N}=83\end{array}$ & $\begin{array}{l}\text { Erenumab } 70 \mathrm{mg} \\
\mathbf{N}=68\end{array}$ & $\begin{array}{l}\text { Erenumab } 140 \mathrm{mg} \\
\boldsymbol{N}=81\end{array}$ \\
\hline Migraine days per month & & & 81 \\
$\mathrm{~N}$ & 83 & 68 & $-3.5(-4.3,-2.8)$ \\
Change from baseline, LSM (95\% Cl) & $-1.4(-2.2,-0.7)$ & $-3.2(-4.0,-2.4)$ & $-2.1(-3.1,-1.1) P<0.001$
\end{tabular}

Acute MSMD per month among patients taking acute migraine-specific medications at baseline

$\mathrm{N}$

Change from baseline, LSM (95\% Cl)

Difference from placebo, LSM (95\% CI)
48

$-0.4(-1.1,0.3)$
38

$-2.0(-2.8,-1.2)$

$-1.6(-2.6,-0.6) P=0.002$
51

$-2.8(-3.5,-2.1)$

$-2.4(-3.4,-1.4) P<0.001$

Patients with $\geq 50 \%$ reduction from baseline in migraine days per month ( $\geq 50 \%$ response)

$\begin{array}{llll}\mathrm{N} & 83 & 68 & 81 \\ \mathrm{n}(\%) & 21(25.3) & 29(42.6) & 40(49.4) \\ \mathrm{OR}^{\mathrm{a}}(95 \% \mathrm{Cl}) & & 2.2(1.1,4.4) P=0.024 & 2.8(1.5,5.5) P=0.002\end{array}$

The analysis included randomized patients who received $\geq 1$ dose of investigational product and had $\geq 1$ postbaseline measurement during the double-blind treatment phase. Change from baseline in MMD and monthly acute MSMD was analyzed using a generalized linear mixed effects model, which included treatment, visit, treatment by visit interaction, stratification factors (North America/other and naïve/prior use/concomitant use), and baseline value as covariates and assumed a first-order autoregressive covariance structure; missing data were not imputed. The proportion of responders was analyzed using a stratified Cochran-Mantel-Haenszel test after imputation of missing data as nonresponse

Abbreviations: $\mathrm{Cl}$ confidence interval, LSM least squares mean, MSMD migraine-specific medication days, OR odds ratio

${ }^{a}$ The common ORs and $P$ values were obtained from a Cochran-Mantel-Haenszel test, stratified by prior/current treatment with migraine-preventive medication and region

\section{Proportion of patients achieving $\geq 50 \%$ reduction from baseline in monthly migraine days}

Both doses of erenumab vs placebo resulted in a significantly higher proportion of patients achieving at least a $50 \%$ response at each time point except month 4 (Fig. 3). A $\geq 50 \%$ response over months 4-6 was achieved by $25.3 \%, 42.6 \%$, and $49.4 \%$ of patients who received placebo, erenumab $70 \mathrm{mg}$, and erenumab $140 \mathrm{mg}$, respectively. The odds of having a $\geq 50 \%$ response over months
4-6 were $2.2(P=0.024)$ and $2.8(P=0.002)$ times greater for the erenumab 70 and $140 \mathrm{mg}$ groups, respectively, than for the placebo group (Table 2).

\section{Safety}

Erenumab had an overall safety profile comparable to placebo (Table 4). There were no cardiovascular adverse events in this subpopulation of patients.

Table 3 Change From Baseline in Mean Monthly Migraine Days by Hormonal Contraception Status

\begin{tabular}{|c|c|c|c|c|c|c|}
\hline & \multicolumn{3}{|c|}{ Received Hormonal Contraception } & \multicolumn{3}{|c|}{ Did Not Receive Hormonal Contraception } \\
\hline & $\begin{array}{l}\text { Placebo } \\
N=20\end{array}$ & $\begin{array}{l}\text { Erenumab } 70 \mathrm{mg} \\
N=18\end{array}$ & $\begin{array}{l}\text { Erenumab } \\
140 \mathrm{mg} \\
N=27\end{array}$ & $\begin{array}{l}\text { Placebo } \\
N=63\end{array}$ & $\begin{array}{l}\text { Erenumab } 70 \mathrm{mg} \\
N=50\end{array}$ & $\begin{array}{l}\text { Erenumab } 140 \mathrm{mg} \\
N=54\end{array}$ \\
\hline $\begin{array}{l}\text { Monthly migraine days at } \\
\text { baseline, mean (SD) }\end{array}$ & $9.5(3.0)$ & $8.5(2.7)$ & $8.9(2.2)$ & $8.3(2.8)$ & $8.2(2.3)$ & $8.2(2.4)$ \\
\hline $\begin{array}{l}\text { Change from baseline over } \\
\text { months 4-6, LSM (95\% CI) }\end{array}$ & $-1.6(-3.4,0.25)$ & $-2.9(-4.8,-1.0)$ & $-3.9(-5.5,-2.4)$ & $-1.4(-2.2,-0.6)$ & $-3.3(-4.2,-2.4)$ & $-3.4(-4.2,-2.5)$ \\
\hline Difference from placebo & & $\begin{array}{l}-1.3(-3.9,1.2) \\
P=0.3\end{array}$ & $\begin{array}{l}-2.4(-4.7,-0.1) \\
P=0.045\end{array}$ & & $\begin{array}{l}-2.0(-3.1,-0.8) \\
P=0.001\end{array}$ & $\begin{array}{l}-2.0(-3.1,-0.8) \\
P<0.001\end{array}$ \\
\hline
\end{tabular}

Treatment by subgroup $\quad 0.76$

interaction $P$ value

over months 4-6

The analysis included randomized patients who received $\geq 1$ dose of investigational product and had $\geq 1$ postbaseline measurement during the double-blind treatment phase. Change from baseline in MMD and monthly acute MSMD was analyzed using a generalized linear mixed effects model, which included treatment, visit, treatment by visit interaction, stratification factors (North America/other and naïve/prior use/concomitant use), and baseline value as covariates and assumed a first-order autoregressive covariance structure; missing data were not imputed. $P$ values for pairwise comparisons are nominal $P$ values without multiplicity adjustment

Abbreviations: Cl confidence interval, LSM least squares mean 


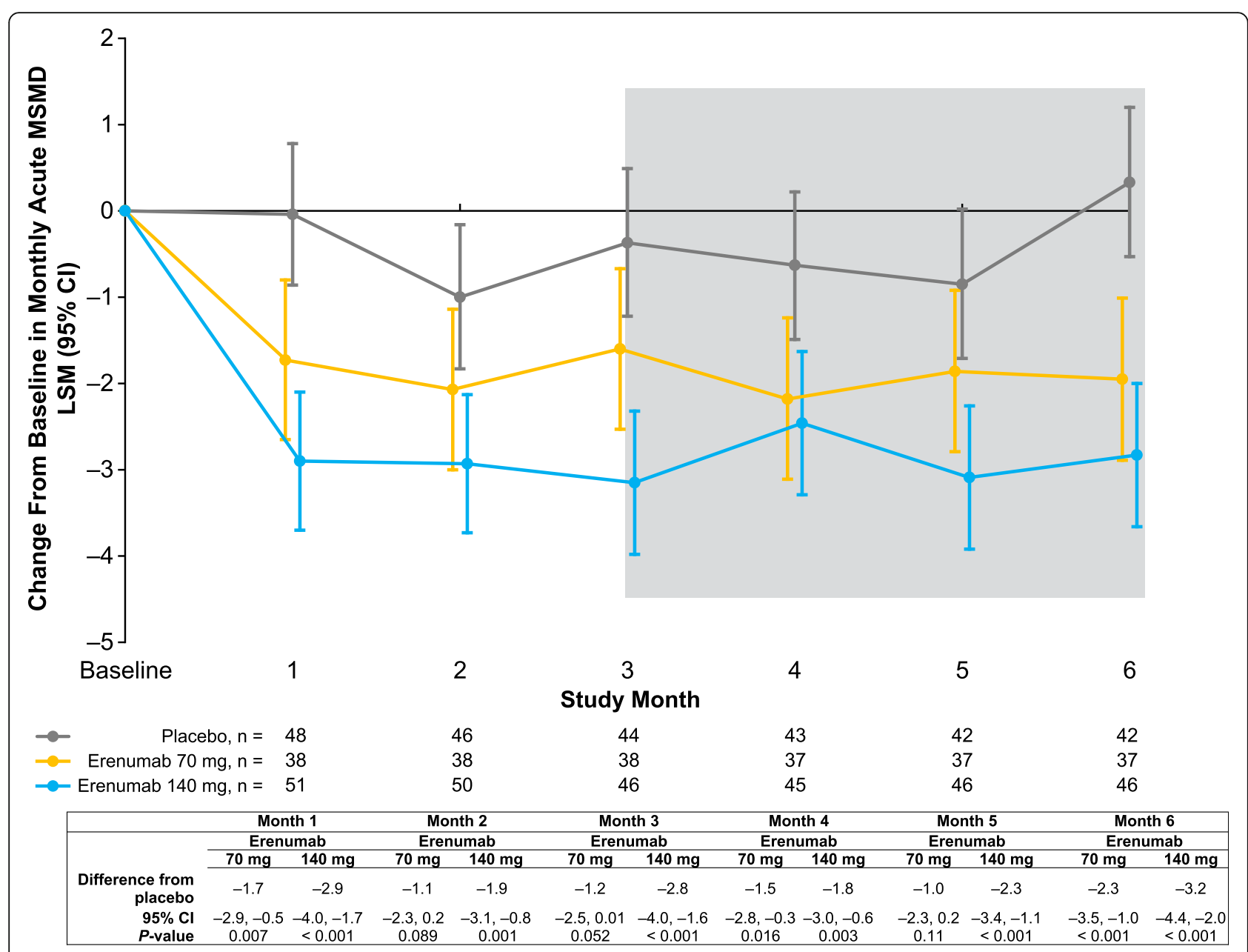

Fig. 2 Change from baseline in monthly acute MSMD among patients with a self-reported history of menstrual migraine who took migrainespecific medications at baseline. Data are shown as LSM with 95\% Cls. The gray shaded area represents months 4-6. Abbreviations: Cl, confidence interval; LSM, least squares mean; MSMD, migraine-specific medication days

\section{Discussion}

Consistent with the overall STRIVE population, preventive treatment with erenumab $70 \mathrm{mg}$ and $140 \mathrm{mg}$ vs placebo resulted in statistically significant improvements in MMD and acute MSMD and achievement of $\geq 50 \%$ response in this subpopulation of patients with a selfreported history of menstrual migraine. The overall incidence of treatment-emergent adverse events was also consistent with the overall STRIVE population.

Because of the frequency and burden of migraine in women with menstrual migraine, the majority qualify for preventive treatment [31]. However, although there are strategies for short-term prevention of menstrual migraine, limited options are available for long-term prevention [14]. It is, therefore, of interest that the efficacy and safety profiles of erenumab in this subgroup were similar to the overall episodic migraine population of STRIVE, in which erenumab significantly reduced the number of MMD and MSMD and increased the odds of achieving $\geq 50 \%$ reduction from baseline in MMD [29]. A subgroup analysis of MMD among women who received hormonal contraception suggests that exogenous hormones do not impact the efficacy of erenumab in this patient population; however, the sample sizes of these subgroups were too small to draw any definitive conclusions. Further investigation appears warranted, as several studies suggest that fluctuations of ovarian steroid hormone levels may modulate CGRP, with high estrogen states being related to an increase in CGRP levels in general, although the exact mechanistic interactions between ovarian steroid hormones and CGRP are not fully understood [32].

The prevalence of menstrual migraine depends on how it is defined and recorded, and there may be substantial differences in prevalence rates of menstrual migraine determined by self-report. For example, in population-based studies [11, 13], the reported prevalence of menstrual migraine is about $20 \%$ of women with 


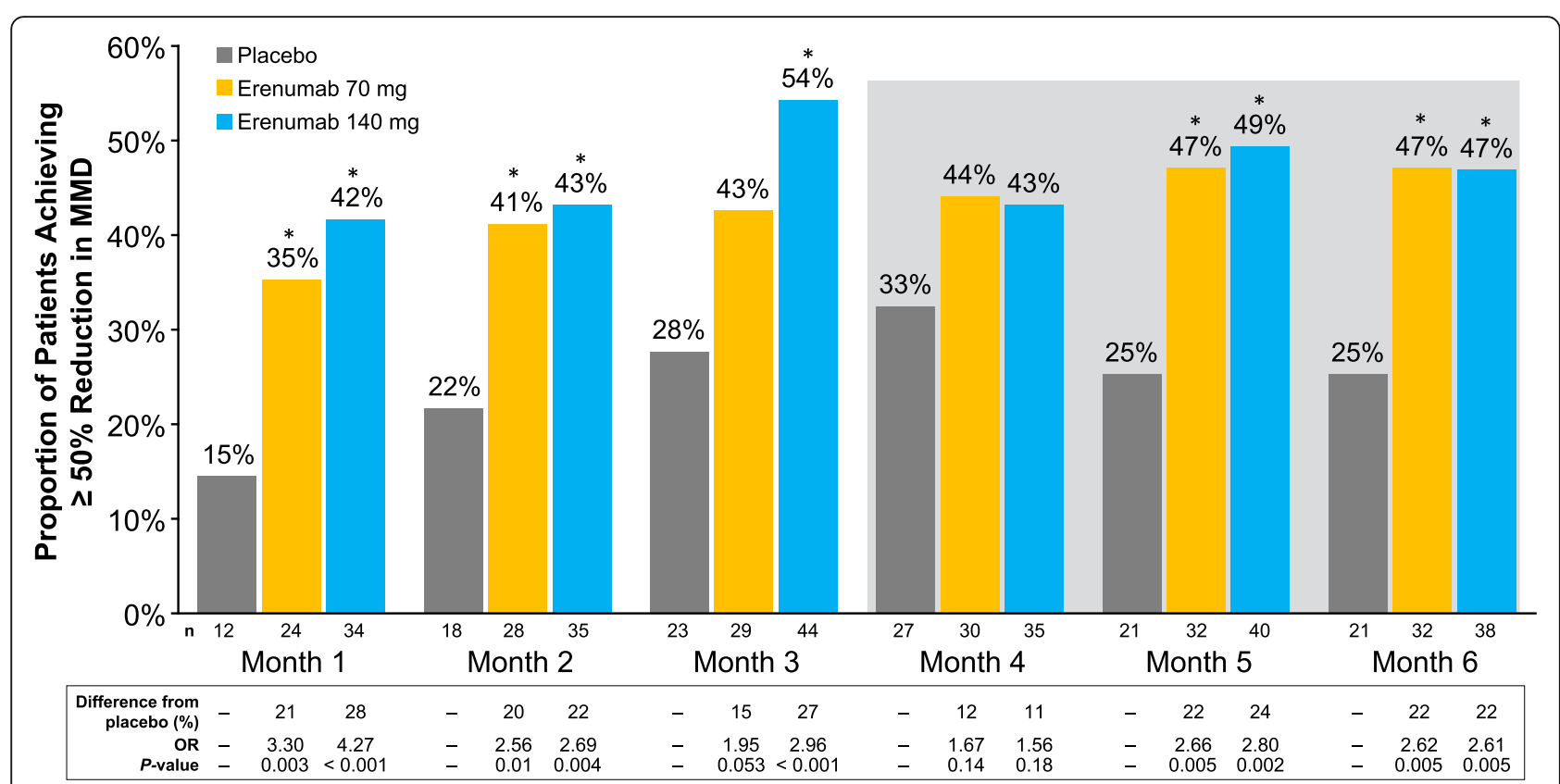

Fig. 3 Proportion of patients achieving $\geq 50 \%$ reduction from baseline in MMD. Data are shown as percentages. The gray shaded area represents months 4-6. *Statistically significantly different from placebo. Abbreviations: MMD, monthly migraine days; OR, odds ratio

Table 4 Incidence of adverse events during the double-blind treatment phase

\begin{tabular}{|c|c|c|c|}
\hline & $\begin{array}{l}\text { Placebo } \\
\boldsymbol{N}=83\end{array}$ & $\begin{array}{l}\text { Erenumab } 70 \mathrm{mg} \\
\boldsymbol{N}=68\end{array}$ & $\begin{array}{l}\text { Erenumab } 140 \mathrm{mg} \\
\boldsymbol{N}=81\end{array}$ \\
\hline All treatment-emergent adverse events, $\mathrm{n}(\%)$ & $56(67.5)$ & $42(61.8)$ & $42(51.9)$ \\
\hline Grade $3^{\mathrm{a}}$ & $5(6.0)$ & $2(2.9)$ & $3(3.7)$ \\
\hline Serious & $2(2.4)$ & $2(2.9)$ & $2(2.5)$ \\
\hline Leading to discontinuation of study drug & $3(3.6)$ & $1(1.5)$ & $3(3.7)$ \\
\hline Fatal & $0(0.0)$ & $0(0.0)$ & $0(0.0)$ \\
\hline \multicolumn{4}{|l|}{ Adverse events in $\geq 2 \%$ of patients, $n(\%)^{b}$} \\
\hline Nasopharyngitis & $10(12.0)$ & $8(11.8)$ & $8(9.9)$ \\
\hline Upper respiratory tract infection & $2(2.4)$ & $6(8.8)$ & $5(6.2)$ \\
\hline Nausea & $3(3.6)$ & $3(4.4)$ & $3(3.7)$ \\
\hline Influenza & $1(1.2)$ & $2(2.9)$ & $3(3.7)$ \\
\hline Insomnia & $0(0.0)$ & $0(0.0)$ & $3(3.7)$ \\
\hline Fatigue & $1(1.2)$ & $2(2.9)$ & $2(2.5)$ \\
\hline Sinusitis & $0(0.0)$ & $2(2.9)$ & $2(2.5)$ \\
\hline Vomiting & $3(3.6)$ & $1(1.5)$ & $2(2.5)$ \\
\hline Injection site erythema & $1(1.2)$ & $1(1.5)$ & $2(2.5)$ \\
\hline Urinary tract infection & $5(6.0)$ & $2(2.9)$ & $1(1.2)$ \\
\hline Headache & $0(0.0)$ & $2(2.9)$ & $1(1.2)$ \\
\hline Cardiovascular events, n (\%) & $0(0.0)$ & $0(0.0)$ & $0(0.0)$ \\
\hline
\end{tabular}

Adverse events were graded using CTCAE version 4.03. All serious adverse events were single-occurrence events Abbreviations: CTCAE Common Terminology Criteria for Adverse Events

${ }^{\text {a }}$ There were no grade 4 adverse events

bln any of the treatment groups

'Based on the following search criteria: ischemic central nervous system vascular conditions, ischemic heart disease, and peripheral arterial disease 
migraine (approximately $7 \%$ of the general female population), compared with $11 \%$ of women with migraine when prospectively assessed in the context of clinicbased studies [33]. The prevalence of self-reported menstrual migraine determined in our analysis (28.5\%) is higher than that observed in clinical trials that prospectively assessed menstrual migraine. Although our data on menstrual migraine were collected in the context of a prospective clinical trial, this finding may be due to selfreported data that were not confirmed with headache diaries during the study.

Our exploratory analysis is limited by our inability to differentiate PMM and MRM, and our inability to examine the effect of treatment on intermenstrual vs perimenstrual migraine days. Given that the study required at least 4 MMDs and the fact that 214 (92\%) patients had a baseline MMD $>5$, it is reasonable to conclude that the majority of women likely belonged to the MRM group, experiencing both menstrual and non-menstrual migraine attacks, although this information was not collected. The patients categorized as having menstrual migraine in our study have similar characteristics to "real-world" patients with menstrual migraine, who are generally identified based on retrospective self-report of perimenstrual migraine attacks during clinical encounters with the treating clinician rather than with prospective headache diaries. Similar to the general population [34], approximately onethird of patients with menstrual migraine reported that they were taking oral contraceptives/hormone therapy during the study, which may be an important confounder in terms of efficacy in this subgroup of patients. In addition, women who experience menstrual migraine may be more likely to use continuous contraceptive/hormonal options and may have been misclassified if they were not currently experiencing perimenstrual attacks. Furthermore, the relatively small sample size likely contributed to variability of effect and statistical significance at some time points. Variability was reduced, however, by analyzing the mean monthly efficacy over months $4-6$, the primary prespecified analytic approach.

\section{Conclusions}

In summary, these exploratory data from a large phase 3 study of erenumab in patients with menstrual migraine attacks (including both PMM and MRM subgroups) are consistent with the overall STRIVE episodic migraine population and support the efficacy of erenumab in this specific subgroup of women.

\section{Abbreviations}

CGRP: Calcitonin gene-related peptide; ICHD: The International Classification of Headache Disorders; MMD: Monthly migraine days; MRM: Menstrually related migraine; MSMD: Migraine-specific medication days; PMM: Pure menstrual migraine

\section{Acknowledgments}

Kathryn Boorer, PhD, of KB Scientific Communications, LLC (funded by Amgen Inc.) provided medical writing support for the preparation of this manuscript.

\section{Authors' contributions}

$\mathrm{KP}, \mathrm{HG}$, and JB collected data from patients enrolled in STRIVE. HP, DDM, and FZ were involved in the conception and design of the study. All authors were involved in the analysis and interpretation of the data, contributed to writing the manuscript, and approved the final version.

\section{Funding}

This analysis was funded by Amgen Inc. and Novartis. Trial registration: ClinicalTrials.gov, NCT02456740. Registered 28 May 2015, https:/clinicaltrials. gov/ct2/show/NCT02456740.

\section{Availability of data and materials \\ Qualified researchers may request data from Amgen clinical studies. Complete details are available at http://www.amgen.com/datasharing.}

\section{Ethics approval and consent to participate}

The study protocol was approved by the ethics committee or institutional review board at each clinical site, and all patients provided signed informed consent before the start of any study-related procedures. The study was conducted in accordance with the International Council for Harmonisation Good Clinical Practice Guidelines and conforms to the provisions of the Declaration of Helsinki.

\section{Consent for publication}

Not applicable.

\section{Competing interests}

JMP is a consultant/on advisory boards for Alder Biopharmaceuticals, Allergan, Amgen, Biohaven, Promius Pharma and receives research funding from NIH/NIA K23AG049466-05. KP has received personal compensation from Allergan, Amgen/Novartis, Eli Lilly, and Teva for consulting, serving on a scientific advisory board, and/or speaking and is a clinical trial investigator for Amgen/Novartis (erenumab), Eli Lilly (galcanezumab), and Autonomic Technologies Inc. (sphenopalatine ganglion stimulation). HG has received research support from Allergan, Amgen, Bayer, Novartis, Menarini, and Teva and is a speaker for Allergan, Novartis, and Teva. JB has nothing to disclose. AR is an advisor for Allergan, Amgen, Amneal, Assertio, Autonomic Technologies Inc., Biohaven, Cala Health, Neurolief, Promius, Satsuma, Teva, Theranica, Xoc, and Zosano and is on a speakers' bureau for Amgen and Teva. RK is a consultant for Amgen. FZ is an employee of Amgen Inc. HP and DDM are employees and stockholders of Amgen.

\section{Author details}

${ }^{1}$ Department of Neurology, Montefiore Headache Center, 1300 Morris Park Avenue, Van Etten 3C9, Bronx, NY 10461, USA. ${ }^{2}$ Albert Einstein College of Medicine, Bronx, NY, USA. ${ }^{3}$ Ghent University Hospital, Ghent, Belgium. ${ }^{4}$ Kiel Migraine and Headache Center, Kiel, Germany. ${ }^{5}$ Mercy Clinic Neurology, St Louis, MO, USA. ${ }^{6}$ The David Geffen School of Medicine at UCLA, Los Angeles, CA, USA. ${ }^{7}$ Department of Obstetrics, Gynecology and Reproductive Sciences, University of California, San Francisco, CA, USA. ${ }^{8}$ Sutter East Bay Medical Foundation, Berkeley, CA, USA. ${ }^{9}$ Amgen Inc., Thousand Oaks, CA, USA.

Received: 6 March 2020 Accepted: 27 July 2020

Published online: 03 August 2020

\section{References}

1. Macgregor EA (2009) Menstrual migraine: therapeutic approaches. Ther Adv Neurol Disord 2:327-336. https://doi.org/10.1177/1756285609335537

2. Couturier EG, Bomhof MA, Neven AK, van Duijn NP (2003) Menstrual migraine in a representative Dutch population sample: prevalence, disability and treatment. Cephalalgia 23:302-308. https://doi.org/10.1046/j.1468-2982. 2003.00516.x

3. MacGregor EA, Victor TW, Hu X, Xiang Q, Puenpatom RA, Chen W, Campbell JC (2010) Characteristics of menstrual vs nonmenstrual migraine: a post hoc, within-woman analysis of the usual-care phase of a nonrandomized 
menstrual migraine clinical trial. Headache 50:528-538. https://doi.org/10. $1111 / j .1526-4610.2010 .01625 . x$

4. Granella F, Sances G, Allais G, Nappi RE, Tirelli A, Benedetto C, Brundu B, Facchinetti F, Nappi G (2004) Characteristics of menstrual and nonmenstrual attacks in women with menstrually related migraine referred to headache centres. Cephalalgia 24:707-716. https://doi.org/10.1111/j.1468-2982.2004. 00741.x

5. Pinkerman B, Holroyd K (2010) Menstrual and nonmenstrual migraines differ in women with menstrually-related migraine. Cephalalgia 30:1187-1194. https://doi.org/10.1177/0333102409359315

6. Vetvik KG, Benth JS, MacGregor EA, Lundqvist C, Russell MB (2015) Menstrual versus non-menstrual attacks of migraine without aura in women with and without menstrual migraine. Cephalalgia 35:1261-1268. https:// doi.org/10.1177/0333102415575723

7. Güven B, Güven H, Çomoğlu S (2017) Clinical characteristics of menstrually related and non-menstrual migraine. Acta Neurol Belg 117:671-676. https:// doi.org/10.1007/s13760-017-0802-y

8. Martin VT, Wernke S, Mandell K, Ramadan N, Kao L, Bean J, Liu J, Zoma W, Rebar R (2005) Defining the relationship between ovarian hormones and migraine headache. Headache 45:1190-1201. https://doi.org/10.1111/j.15264610.2005.00242.x

9. Pavlovic JM, Stewart WF, Bruce CA, Gorman JA, Sun H, Buse DC, Lipton RB (2015) Burden of migraine related to menses: results from the AMPP study. J Headache Pain 16:24. https://doi.org/10.1186/s10194-015-0503-y

10. Headache Classification Committee of the International Headache Society (IHS) (2018) The International Classification of Headache Disorders, 3rd edition. Cephalalgia, 38:1-211. https://doi.org/10.1177/0333102417738202

11. Vetvik KG, MacGregor EA, Lundqvist C, Russell MB (2010) Self-reported menstrual migraine in the general population. J Headache Pain 11:87-92. https://doi.org/10.1007/s10194-010-0197-0

12. MacGregor EA, Chia H, Vohrah RC, Wilkinson M (1990) Migraine and menstruation: a pilot study. Cephalalgia 10:305-310. https://doi.org/10.1046/ j.1468-2982.1990.1006305.x

13. Vetvik KG, Macgregor EA, Lundqvist C, Russell MB (2014) Prevalence of menstrual migraine: a population-based study. Cephalalgia 34:280-288. https://doi.org/10.1177/0333102413507637

14. Allais G, Chiarle G, Sinigaglia S, Benedetto C (2018) Menstrual migraine: a review of current and developing pharmacotherapies for women. Expert Opin Pharmacother 19:123-136. https://doi.org/10.1080/14656566.2017. 1414182

15. Allais G, Sanchez del Rio M, Diener HC, Benedetto C, Pfeil J, Schauble B, van Oene J (2011) Perimenstrual migraines and their response to preventive therapy with topiramate. Cephalalgia 31:152-160. https://doi.org/10.1177/ 0333102410378049

16. Nappi RE, Merki-Feld GS, Terreno E, Pellegrinelli A, Viana M (2013) Hormonal contraception in women with migraine: is progestogen-only contraception a better choice? J Headache Pain 14:66. https://doi.org/10.1186/1129-2377-14-66

17. Massiou H, MacGregor EA (2000) Evolution and treatment of migraine with oral contraceptives. Cephalalgia 20:170-174. https://doi.org/10.1046/j.14682982.2000.00038.x

18. Macgregor EA, Hackshaw A (2002) Prevention of migraine in the pill-free interval of combined oral contraceptives: a double-blind, placebo-controlled pilot study using natural oestrogen supplements. J Fam Plann Reprod Health Care 28:27-31. https://doi.org/10.1783/147118902101195974

19. Tepper DE (2014) Headache toolbox: menstrual migraine. Headache 54:403408. https://doi.org/10.1111/head.12279

20. Sacco S, Merki-Feld GS, Ægidius KL, Bitzer J, Canonico M, Gantenbein AR, Kurth T, Lampl C, Lidegaard O, MacGregor EA, MaassenVanDenBrink A, Mitsikostas DD, Nappi RE, Ntaios G, Paemeleire K, Sandset PM, Terwindt GM, Vetvik KG, Martelletti P, European Headache Federation (EHF), the European Society of Contraception and Reproductive Health (ESCRH) (2018) Effect of exogenous estrogens and progestogens on the course of migraine during reproductive age: a consensus statement by the European Headache Federation (EHF) and the European Society of Contraception and Reproductive Health (ESCRH). J Headache Pain 19:76. https://doi.org/10. 1186/s10194-018-0896-5

21. Xu Z, Li Y, Tang S, Huang X, Chen T (2015) Current use of oral contraceptives and the risk of first-ever ischemic stroke: a meta-analysis of observational studies. Thromb Res 136:52-60. https://doi.org/10.1016/j. thromres.2015.04.02
22. Sacco S, Merki-Feld GS, Egidius KL, Bitzer J, Canonico M, Kurth T, Lampl C, Lidegaard O, MacGregor EA, MaassenVanDenBrink A, Mitsikostas DD, Nappi RE, Ntaios G, Sandset PM, Martelletti P, European Headache Federation (EHF), the European Society of Contraception and Reproductive Health (ESCRH) (2017) Hormonal contraceptives and risk of ischemic stroke in women with migraine: a consensus statement from the European Headache Federation (EHF) and the European Society of Contraception and Reproductive Health (ESCRH). J Headache Pain 18:108. https://doi.org/10. 1186/s10194-017-0815-1

23. Ornello R, Canonico M, Merki-Feld GS, Kurth T, Lidegaard O, MacGregor EA, Lampl C, Nappi RE, Martelletti P, Sacco S (2020) Migraine, low-dose combined hormonal contraceptives, and ischemic stroke in young women: a systematic review and suggestions for future research. Expert Rev Neurother 20:313-317. https://doi.org/10.1080/14737175.2020.1730816

24. Sheikh HU, Pavlovic J, Loder E, Burch R (2018) Risk of stroke associated with use of estrogen containing contraceptives in women with migraine: a systematic review. Headache 58:5-21. https://doi.org/10.1111/head.13229

25. Committee on Practice Bulletins-Gynecology (2019) ACOG Practice Bulletin No. 206: Use of hormonal contraception in women with coexisting medical conditions. Obstet Gynecol 133:e128-e150. https://doi.org/10.1097/ AOG.0000000000003072.

26. Steiner TJ, Jensen R, Katsarava Z, Linde M, MacGregor EA, Osipova V, Paemeleire K, Olesen J, Peters M, Martelletti P (2019) Aids to management of headache disorders in primary care (2nd edition): on behalf of the European Headache Federation and Lifting The Burden: the Global Campaign against Headache. J Headache Pain 20:57. https://doi.org/10. 1186/s10194-018-0899-2

27. World Health Organization (2015) Medical eligibility criteria for contraceptive use, 5th edition. https://apps.who.int/iris/bitstream/handle/1 0665/181468/9789241549158_eng.pdf

28. Shi L, Lehto SG, Zhu DX, Sun H, Zhang J, Smith BP, Immke DC, Wild KD, Xu C (2016) Pharmacologic characterization of AMG 334, a potent and selective human monoclonal antibody against the calcitonin gene-related peptide receptor. J Pharmacol Exp Ther 356:223-231. https:/doi.org/10.1124/jpet.115.227793

29. Goadsby PJ, Reuter U, Hallstrom Y, Broessner G, Bonner JH, Zhang F, Sapra S, Picard H, Mikol DD, Lenz RA (2017) A controlled trial of erenumab for episodic migraine. N Engl J Med 377:2123-2132

30. Gold EB (2011) The timing of the age at which natural menopause occurs. Obstet Gynecol Clin N Am 38:425-440. https://doi.org/10.1016/.jogc.2011.05.002

31. Lipton RB, Bigal ME, Diamond M, Freitag F, Reed ML, Stewart WF, AMPP Advisory Group (2007) Migraine prevalence, disease burden, and the need for preventive therapy. Neurology 68:343-349. https://doi.org/10.1212/01. wnl.0000252808.97649.21

32. Labastida-Ramirez A, Rubio-Beltran E, Villalon CM, MaassenVanDenBrink A (2019) Gender aspects of CGRP in migraine. Cephalalgia 39:435-444. https:// doi.org/10.1177/0333102417739584

33. Dowson AJ, Massiou H, Aurora SK (2005) Managing migraine headaches experienced by patients who self-report with menstrually related migraine: a prospective, placebo-controlled study with oral sumatriptan. J Headache Pain 6:81-87. https://doi.org/10.1007/s10194-005-0156-3

34. Kavanaugh ML, Jerman J (2018) Contraceptive method use in the United States: trends and characteristics between 2008, 2012 and 2014. Contraception 97:14-21. https://doi.org/10.1016/j.contraception.2017.10.003

\section{Publisher's Note}

Springer Nature remains neutral with regard to jurisdictional claims in published maps and institutional affiliations.

\section{Ready to submit your research? Choose BMC and benefit from:}

- fast, convenient online submission

- thorough peer review by experienced researchers in your field

- rapid publication on acceptance

- support for research data, including large and complex data types

- gold Open Access which fosters wider collaboration and increased citations

- maximum visibility for your research: over $100 \mathrm{M}$ website views per year

At BMC, research is always in progress.

Learn more biomedcentral.com/submissions 